\title{
A STUDY OF BREATHLESSNESS IN PREGNANT FEMALES IN A RURAL SETUP
}

\author{
Amandeep Singh Kaloti ${ }^{1}$, Anoop Chhabra², E. Chandrasekaran ${ }^{3}$ \\ ${ }^{1}$ Associate Professor, Department of Medicine, SGT Medical College, Budhera, Gurgaon. \\ ${ }^{2}$ Associate Professor, Department of Medicine, SGT Medical College, Budhera, Gurgaon. \\ 3Professor, Department of Medicine, SGT Medical College, Budhera, Gurgaon.
}

\section{ABSTRACT}

AIM

This cross-sectional study was done to know the number of pregnant females experiencing breathlessness. Breathlessness is a common but a less recognised symptom in pregnancy. This study was done to highlight the fact that breathlessness is a common symptom in pregnancy. Conditions like anaemia were also investigated as anaemia is also a common cause of breathlessness and pregnant females are more prone to anaemia.

\section{MATERIALS AND METHODS}

4100 patients admitted in the wards and attending the OPD of the hospital were studied in the 1 year period and pulmonary function tests were done and $\mathrm{Hb} \%$ was done. Pregnant females with previous medical problems were excluded from the study.

\section{RESULTS}

We found in the study that 2870 patients (70\%) had a decrease in the ERV, while 2788 patients (68\%) had a decrease in RV. 2255 patients (55\%) were anaemic. Overall, 3114 patients i.e. $75.95 \%$ patients experienced breathlessness. Anaemia was an important comorbid factor in patients experiencing breathlessness.

\section{CONCLUSION}

Our study concludes that some amount of breathlessness is common in pregnancy and more so if the patient is anaemic. This is in concordance with the literature.

\section{KEYWORDS}

Breathlessness, Pregnant Females, Anaemia, PFT.

HOW TO CITE THIS ARTICLE: Kaloti AS, Chhabra A, Chandrasekaran E. A study of breathlessness in pregnant females in a rural setup. J. Evolution Med. Dent. Sci. 2016;5(35):2022-2024, DOI: 10.14260/jemds/2016/475

\section{INTRODUCTION}

A variety of physiologic adaptations to the maternal respiratory system occur in the normal pregnancy. Minute ventilation increases, attributable mainly to the effect of high progesterone levels on the maternal respiratory center. Oxygen consumption rises and residual lung volume decreases particularly in the latter half of the pregnancy. Generally, these physiology changes are well tolerated with minimal symptomatology by the pregnant woman. The interaction of these biologic changes with various pulmonary symptoms is less well understood. ${ }^{1}$

It is a clinical challenge to differentiate benign breathlessness of pregnancy from more serious causes of the shortness of breath in pregnancy such as asthma, pulmonary embolism, and cardiomyopathy. Initial evaluation should be based on a careful history and physical examination. Dyspnoea attributable to pregnancy physiology alone is generally episodic, insidious in onset, and not associated with any chest discomfort, cough or sudden exacerbation.

Financial or Other, Competing Interest: None.

Submission 16-03-2016, Peer Review 10-04-2016,

Acceptance 16-04-2016, Published 02-05-2016.

Corresponding Author:

Dr. Amandeep Singh Kaloti,

H. No.1231, Urban Estate,

Phase 1, Jalandhar,

Punjab-144022.

E-mail: amansaini1231@rediffmail.com

DOI: $10.14260 /$ jemds/2016/475
A previous history of reactive airways, presence of cough or wheezing, or an obstructive pattern on PFT may point to asthma as a cause. Pulmonary embolism is usually characterised by the sudden outset of dyspnoea or chest pain, often in association with asymmetrical leg symptoms/signs. Cardiac disease in pregnancy may present with dyspnoea as an initial or predominant feature. This may reflect a preexisting cardiac condition, unmasked by the increased blood volume and cardiac work of pregnancy or may point to a new onset of cardiac disease such as peripartum cardiomyopathy. Findings on physical examination of tachypnoea, tachycardia, elevated jugular venous pulse, a concerning murmur, respiratory crackles on auscultation, or an abnormal chest Xray or ECG (Electrocardiogram) can point to a cardiac cause of dyspnoea. ${ }^{1}$

The initial pulmonary function test obtained is spirometry. This study is an effort dependent test used to asses for obstructive pathophysiology as seen in asthma, COPD, and bronchiectasis. A diminished forced expiratory volume in $1 \mathrm{sec}\left(\mathrm{FEV}_{1}\right) /$ forced vital capacity (FVC) often defined as $<70 \%$ of the predicted value is diagnostic of the obstruction. In addition to measuring the FEV1 and FVC, the clinician should examine the flow-volume loop (which is effort dependent). A plateau of the inspiratory and expiratory curves suggests large airway obstruction in extrathoracic and the intrathoracic locations respectively. Spirometry and symmetrical decrease in $\mathrm{FEV}_{1}$ and FVC warrants further testing, including measurement of lung volumes and the diffusion capacity of the lung for carbon monoxide. 
A total lung capacity $<80 \%$ of the predicted value for a patient's age, race, sex and height defines the restrictive pathophysiology. Restriction can result from parenchymal disease, neuromuscular weakness, or chest wall or pleural disease. Normal spirometry, normal lung volumes and a low $\mathrm{D}_{\mathrm{L}} \mathrm{Co}$ should prompt further evaluation for pulmonary vascular disease. ${ }^{2}$

Pregnancy is associated with several significant changes in respiratory function. Pregnant women increase their minute ventilation by nearly $50 \%$. This is achieved by increasing the volume of each breath rather than by increasing respiratory rate. This is an effect of progesterone, leading to a decrease in arterial carbon dioxide pressure $\left(\mathrm{PaCO}_{2}\right)$ to 27 to $32 \mathrm{mmHg} .{ }^{3}$ Arterial oxygen pressure $\left(\mathrm{PaO}_{2}\right)$ is increased to 95 to $105 \mathrm{mmHg}$ at sea level, as per the alveolar gas equation. A compensatory renal excretion of bicarbonate occurs in response to the chronic respiratory alkalosis, and serum bicarbonate levels normally decrease by approximately $4 \mathrm{mEq} / \mathrm{L} .4$

Pulmonary function test (PFT) results, including forced expiratory volume in 1 second (FEV1), forced vital capacity (FVC) and peak exploratory flow rate (PEFR) remain largely unchanged in pregnancy. The main change seen on PFT is an approximately $20 \%$ drop in FRC (that portion of a breath that can still be exhaled after normal resting exhalation), due to a decrease in both expiratory reserve volume (ERV) and residual volume (RV).5,6 Although the diaphragm may be elevated to $4 \mathrm{~cm}$ above its usual position by term, this does not have a significant effect on respiratory function because diaphragmatic excursion is not altered.

Mild breathlessness is a common symptom in normal pregnancy and therefore does not necessarily indicate cardiorespiratory disease. Up to $70 \%$ of pregnant females will report some level of dyspnoea. The most typical description of this would be "Air hunger".5,7 This symptom may appear in the late first or early second trimester though the peak for the onset of breathlessness is 28 to 31 wks. gestation. Often the breathlessness occurs spontaneously at rest rather than in association with exertion. The trigger of the symptomatology has not been clearly defined, although the hormonal effect of progesterone on ventilation and the associated fall in $\mathrm{PaCO}_{2}$ seem to be central features. Studies have found that the presence of dyspnoea during pregnancy correlates with a relatively high baseline non-pregnant $\mathrm{PaCO}_{2}$ and low $\mathrm{PaCO}_{2}$ during pregnancy. ${ }^{8}$

Anaemia is one of the most common medical disorders in pregnancy with a $75 \%$ prevalence in some developing countries. Anaemia is defined as a significant reduction in the haemoglobin level or the number of circulating red blood cells. This results in a decrease in the oxygen carrying capacity of the blood. Mild anaemia is usually asymptomatic but more severe anaemia may result in breathlessness. The haemoglobin concentration reaches its nadir at about 20 weeks of gestation and increase slowly from about 30 weeks until term. ${ }^{9}$ The US Centres for Disease Control and Prevention (CDC) condemns anaemia to be defined by a haemoglobin of $<11 \mathrm{~g} / \mathrm{dL}$ in first and third trimester and $<10.5 \mathrm{~g} / \mathrm{dL}$ in the second trimester. ${ }^{9}$ In developing countries, anaemia is associated with up to $13 \%$ of maternal deaths. ${ }^{10}$ Iron dependent enzymes in every cell are affected causing dyspnoea.

Marked physiologic changes in the composition of the blood occur in healthy pregnancy. Increased total blood volume and haemostatic changes help to combat the hazard of haemorrhage at delivery. Plasma volume increases by $50 \%$ and red cell mass by $18 \%$ to $25 \%$, depending on the iron status. These changes cause a physiologic dilution in haemoglobin concentration that is greatest at 32 weeks of gestation. In iron-replete women, haemoglobin returns to normal by 1 week postpartum. Vegetarians are at an additional disadvantage because heme iron (derived from meat) is more readily absorbed than non-heme iron and heme iron also facilitates the absorption of non-heme iron in a mixed diet. Tissue enzyme malfunction occurs even in the early stages of iron deficiency. This might explain the reported association between anaemia during and preterm birth and the anecdotal evidence that blood loss at delivery is greater in women with anaemia.

In normal pregnancy, hypervolemia modifies the response to blood loss. Blood volume decreases after the acute loss at delivery but remains relatively stable as long as the loss does not exceed $25 \%$ of pre-delivery volume. No compensatory increase in blood volume occurs and plasma volume decreases gradually, primarily because of diuresis. Thus, haematocrit gradually increases and blood volume returns to non-pregnant values. ${ }^{11}$

Studies suggest that behavioural abnormalities occur in children with iron deficiency and anaemia. Adult hypertension can also be prevented by treatment of iron deficiency in pregnancy. ${ }^{12}$

Megaloblastic anaemia in pregnancy is nearly always secondary to folic acid deficiency. Plasma folic acid levels decrease as pregnancy advances reaching approximately half of non-pregnant values at term. Explanations for the reduction in folic acid levels include reduced dietary folate intake because of loss of appetite, increased plasma clearance of folate by the kidneys, transfer of folic acid from the mother to the foetus (about $800 \mathrm{mg}$ at term) and uterine hypertrophy and expanded red cell mass. The incidence is higher in multiple pregnancies and closely spaced successive pregnancies. Child is at risk of developing cleft lip and palate and most importantly neural tube defects. ${ }^{11}$

Vitamin B12 deficiency occurs in women who smoke. In the child, this deficiency causes anaemia and failure to thrive. There can be other causes of anaemia like sickle cell disease, thalassaemia, haemolytic anaemia and aplastic anaemia. ${ }^{11}$

\section{AIM \& OBJECTIVE}

To determine the cause of breathlessness in pregnant females in the 28-40 weeks of gestation.

\section{Inclusion Criteria}

All pregnant females between 28-40 weeks of gestation attending the OPD and admitted in the wards of the hospital.

\section{Exclusion Criteria}

Pregnant females with medical conditions like previous heart disease, hypertension, asthma, diabetes mellitus, previous thyroid disease were excluded from the study.

\section{MATERIALS AND METHODS}

This was cross-sectional study done at SGT Medical College \& Research Institute, Budhera, Gurgaon in the Department of Medicine after approval by the Ethics Committee. The study period was from 1st June 2013 to 31st May 2014. 
Data was collected regarding the patients from the patient records of the patient attending the OPD and admitted in the obstetric wards of the hospital. Demographic details, pre-existing medical problems of the patients were enquired.

Informed consent regarding the study was taken from all the patients. Patients were explained in detail about the purpose of the study and that no risk of any kind to the health of the pregnant females is involved was explained. Those not willing to participate were excluded from the study. Also those patients not willing for the investigations were also excluded.

Data related to the Pulmonary Function Test (PFT), oxygen inhalation whether required in the patients, investigations like complete blood count was gathered. A total of 4100 patients who were willing to participate in the study were studied during this period and breathlessness was looked for in them.

\begin{tabular}{|c|c|c|}
\hline Age (Yrs.) & No. of Cases (n=4100) & $\mathbf{\%}$ \\
\hline $18-20$ & 615 & $15 \%$ \\
\hline $21-25$ & 1640 & $40 \%$ \\
\hline $26-30$ & 1230 & $30 \%$ \\
\hline $31-35$ & 410 & $10 \%$ \\
\hline $36-40$ & 205 & $5 \%$ \\
\hline$>40$ & 0 & $0 \%$ \\
\hline \multicolumn{2}{|c|}{ Table I: Age Distribution of Patients } \\
\hline
\end{tabular}

\begin{tabular}{|c|c|c|}
\hline Test Parameter & No. of Cases & $\mathbf{\%}$ \\
\hline FEV1 & 0 & 0 \\
\hline FVC & 0 & 0 \\
\hline PEFR & 0 & 0 \\
\hline ERV & 2870 & $70 \%$ \\
\hline RV & 2788 & $68 \%$ \\
\hline \multicolumn{2}{|c|}{ Table II: Pulmonary Function Test Derangement }
\end{tabular}

\begin{tabular}{|c|c|}
\hline$<11 \mathrm{~g} / \mathrm{dL}$ & $>11 \mathrm{~g} / \mathrm{dL}$ \\
\hline $2255(55 \%)$ & $1845(45 \%)$ \\
\hline \multicolumn{2}{|c|}{ Table III: Haemoglobin Level in Patients } \\
\hline
\end{tabular}

\begin{tabular}{|c|c|c|}
\hline Association Parameter & No. of Cases & \% \\
\hline PFT deranged & 1108 & 27.02 \\
\hline Anaemic & 2006 & 48.93 \\
\hline \multicolumn{2}{|c|}{ Table IV: Breathlessness Association } \\
\hline
\end{tabular}

\begin{tabular}{|c|c|c|}
\hline Intervention & No. of Cases & \% \\
\hline Oxygenation & 205 & 5 \\
\hline Mechanical Ventilation & 0 & 0 \\
\hline \multicolumn{2}{|c|}{ Table V: Intervention Required in Patients } \\
\hline
\end{tabular}

\section{DISCUSSION}

Most of the pregnant females were between 21-25 yrs. of age (1640, i.e. $40 \%$ ) while 1230 i.e. $30 \%$ were between $26-30$ yrs. of age group, 615 (15\%) were between 18-20 yrs., lesser were in the older age group. This shows that most of the females in the study were in the adult age group.

Pulmonary function tests showed that 2870 patients (70\%) had a decrease in ERV, while 2788 patients (68\%) had a decrease in RV. This was consistent with the previous studies. ${ }^{5,6}$ Out of these, $27 \%$ of cases, i.e. 1108 patients experienced breathlessness. This shows that the physiologic changes of pregnancy lead to alterations in the PFT results which in turn are associated with a symptom of breathlessness in a large number of patients. This is consistent with the literature.5,7 2255 patients (55\%) were anaemic according to WHO criteria. ${ }^{11,12}$ Out of these, 2006 (88.96\%) patients experienced breathlessness. So, anaemia is a common associated factor in patients experiencing breathlessness.

Intervention in the form of oxygenation was required in 5\% i.e. 205 patients. Mechanical ventilation was not required in any patient. This shows that the breathlessness in pregnancy is not so severe as to warrant the need of drastic measures like mechanical ventilation. Most of the patients were young and most had a derangement of ERV and RV and more than half the population was anaemic. Breathlessness was experienced by 3114 patients i.e. $75.95 \%$ of the patients. So some amount of breathlessness was experienced by most of the pregnant females which is consistent with the other studies. .5

\section{CONCLUSION}

We conclude by this study that breathlessness is a common symptom in pregnant females in their second and third trimesters. Some amount of breathlessness is experienced by most of the pregnant females. This is usually due to the physiologic changes that occur in the pregnancy. The breathlessness is usually not that severe as to warrant the need of such drastic measures like mechanical ventilation. Early recognition of the more serious causes which are treatable like anaemia leads to better outcomes in the pregnancy.

\section{REFERENCES}

1. James, Steer, Weiner, et al. High risk pregnancy. Elsevier 2010; $4^{\text {th }}$ edn:657-8.

2. Kasper, Fauci, Hauser, et al. Harrison's principles of internal medicine. McGraw Hill 19th Edn, 2015;Vol 2:pg 1661.

3. Saaresranta $T$, Irjala $K$, Polo 0 . Effect of medroxy progesterone on arterial blood gases, leptin. Eur Resp J 2002;20:1413-8.

4. Garcia Rio F, Pino JM, Gomez L, et al. Regulation of breathing and perception of dyspnea in healthy pregnant women. Chest 1996;110(2):446-53.

5. Shailaja Y, Srikanth S. Lung function tests in different trimesters of pregnancy. Indian Journal of Basic and Applied Medical Research 2013;3(1):285-92.

6. Gupta L, Dixit R. A linear study of pulmonary function tests in normal pregnant and non pregnant women. J Indian Med Assoc 2013;111(10):666-9.

7. Lehmann V. Dyspnoea in pregnancy. J Pernat Med 1975;3(3):154-60.

8. Omo Aghoja L. Maternal and fetal acid-base chemistry: a major determinant of perinatal outcome. Ann Med Health Sci Res 2014;4(1):8-17.

9. Jagdish Kumar K, Asha N, Sirinivasa Murthy D, et al. Maternal anaemia in various trimesters and its effects on new born weight and maturity: an observational study. Int J Prev Med 2013;4(2):193-9.

10. Elise M Laflamme. Maternal haemoglobin concentration and pregnancy outcome: a study of effects of elevation in el alto, Bolivia. McGill J Med 2011;13(1):47.

11. James, Steer, Weiner, et al. High risk pregnancy. Elsevier 2010; $4^{\text {th }}$ edn:683.

12. Raymond O Powrie, Michael F Greene, William Camann. Medical disorder in obstetric practice. Blackwell Publishing Ltd 2010; $5^{\text {th }}$ edn:681. 